Jurdimas (Jurnal Pengabdian Kepada Masyarakat) Royal

Vol. 5 No. 1, Januari 2022, hlm. 73 - 78

Available online at https:/jurnal.stmikroyal.ac.id/index.php/jurdimas

\title{
PEMBUATAN SIGNAGE KAWASAN DI KAMPUNG ROMANTIS KOTA MALANG SEBAGAI DESA TEMATIK
}

\author{
Wiwik Dwi Susanti ${ }^{1 *}$, Wendy Sunarya ${ }^{1}$, Masnuna $^{2}$ \\ ${ }^{1}$ Program Studi Arsitektur, Universitas Pembangunan Nasional "Veteran" Jawa Timur \\ ${ }^{2}$ Program Studi Desain Komunikasi Visual, Universitas Pembangunan Nasional "Veteran" \\ Jawa Timur \\ email: *wiwikds.ar@upnjatim.ac.id
}

\begin{abstract}
Kampung Romantis is one of the urban villages in Malang City which currently transforms to be a village with special interest. One of the potentials in Kampung Romantis is the decorative-plant tour and business developed by its residents. This potential can be utilized to strengthen the character of the village that upholds good relations between neighbors and families. Reviewing the standard of a tourism village, Kampung Romantis is still far from the existing standard due to a lack of adequate facilities and infrastructure. However, its location is strategic as located in the middle of the city and near shopping centers, educational and heritage areas. Considering its strategic location and high interest of the residents in developing their village, it is important to branding the area of this village visually. An effort was made through this service program through the signage design for as a logo of Kampung Romantis which can strengthen the image of that area. The stages of theservice program started from observation and communication with the residents, then planning and construction for the signage design. This program had successfully produced a signage design that was constructed to branding the area of Kampung Romantis by involving the residents.
\end{abstract}

Keywords: regional signage; romantic village; thematic village

Abstrak: Kampung romantis merupakan salah satu kampung kota di Kota Malang yang saat ini berupaya untuk menjadi kampung minat khusus. Wisata belanja tanaman hias yang merupakan potensi yang sekarang dapat dikembangkan oleh warganya sendiri. Potensi tersebut dapat dimanfaatkan sebagai untuk memperkuat identitas kawasan sebagai kampung kota yang tetap mengedepankan hubungan yang baik dengan tetangga dan juga keluarga. Apabila dikaji berdasarkan standar kampung wisata, maka kampung romantis masih jauh dari standar yang ada karena sarana dan prasarananya masih minim. Lokasi kampung romantis sangat strategis karena terletak ditengah Kota Malang dan juga dekat dengan pusat perbelanjaan, area pendidikan dan juga kawasan heritage (warisan) yang ada di Kota Malang. Melihat lokasinya yang strategis serta tingginya minat warganya untuk mengembangkan menjadi kampung wisata, maka diperlukan upaya untuk dapat membranding kawasan tersebut dan juga mempercantik secara visual kawasan tersebut. Upaya yang dilakukan dalam kegiatan pengabdian ini melalui desain signage berupa logo dari kampung romatis untuk dapat memperkuat branding kawasan tersebut. Tahapan kegiatan pengabdian dimulai dari observasi dan komunikasi dengan warga hingga perencanaan dan konstruksi signage. Kegiatan pengabdian ini berhasil membuat rancangan signage yang akhirnya dapat dibangun untuk branding di Kawasan kampung romantis dengan keterlibatan warganya.

Kata kunci: desa tematik; kampung romantis; signage 
Jurdimas (Jurnal Pengabdian Kepada Masyarakat) Royal

Vol. 5 No. 1, Januari 2022, hlm. 73 - 78

ISSN 2614-7912 (Print)

DOI: https://doi.org/10.33330/jurdimas.v5i1.1216

ISSN 2622-3813 (Online)

Available online at https:/jurnal.stmikroyal.ac.id/index.php/jurdimas

\section{PENDAHULUAN}

Kota Malang merupakan salah satu Kota di Jawa Timur yang perkembangan wisatanya sangat cepat. Salah satu wisata andalan yaitu wisata muatan khusus dengan mengembangkan potensi kampung kota. Kampung warna-warni, kampung biru, kampung putih, kampung heritage (warisan) merupakan beberapa contoh kampung muatan khusus yang dikembangkan di Kota Malang. Wisata muatan khusus pada saat ini menjadi trend pariwisata karena untuk menghindari wisata masal (Wiwin, 2019).

Keberagaman kampung tersebut merupakan salah satu upaya dari pemerintah, program CSR dan juga kerjasama masyarakat dalam mengembangkan dan ajang promosi kampung kota. Salah satunya yaitu kampung romantis di Bareng Kulon yang juga memiliki keinginan untuk mengembangkan kampungnya menjadi salah satu destinasi wisata baru di Kota Malang. Kampung wisata merupakan suatu bentuk integrasi yang direncanakan oleh pemerintah serta pelaku (masyarakat) yang dilengkapi dengan fasilitas-fasilitas penunjang dalam tatanan kehidupan masyarakat. Tetapi dalam hal ini fasilitas serta perencanaan yang disajikan dalam struktur kehidupan masyarakat adalah seni budaya, serta tradisi yang berlaku di daerah tersebut. Kampung wisata bertujuan untuk menghibur wisatawan, memberikan pelajaran-pelajaran baru dalam hal seni, budaya, dan sejarah untuk dilestarikan terutama di daerah kampung (Ramadhana, Rahardjo, \& Wipranata, 2019).

Lokasi kampung romantis yang terletak tepat dipusat kota Malang menjadikan kampung ini sangat mudah diakses oleh wisatawan. Beberapa objek wisata lain yang berdekatan dengan kampung romantis ini adalah Ijen Boulevard, kampung heritage, museum Brawijaya, pusat perbelanjaan dan juga Kawasan Pendidikan di Kota Malang. Kampung romantis lahir dari ide bahwa kampung merupakan miniatur negara Indonesia yang identik dengan sifat gotong royong dan guyubnya (Nurjani, 2021), sehingga romantis dalam hal ini yaitu menjalin hubungan baik antara tetangga dan juga keluarga. Suasana romantis dapat diwujudkan dengan bunga, sehingga kampung Bareng Kulon mengembangkannya dan dikolaborasikan dengan kemampuan warga dan merawat dan mengembangkan tanaman hias. Selain lokasi kampung romantis yang sangat strategis karena terletak di pusat kota, kampung romantis memiliki potensi lain yang akan dikembangkan yaitu budidaya tanaman hias.

Hasil wawancara dengan Ketua RT 05 menuturkan, bahwa kemampuan warga dalam membudidayakan tanaman hias dapat mendatangkan keuntungan secara finansial sekaligus dapat menjadi identitas kampung. Perangkat RT dan RW kurang menyadari pentingnya sebuah identitas visual seperti logo sebagai penguat citra merek dari suatu kampung wisata. Kurangnya kesadaran diakibatkan karena kurangnya pemahaman mengenai pembuatan sebuah signage yang sesuai dengan standar dari pembuatan logo serta yang harus sesuai dengan visi, misi dan konsep yang dipakai oleh kampung romantis tersebut sebagai penyampaian citra kawasan (Anggraini \& Nathalia, 2014).

Harapannya bahwa kampung romantis ini tidak hanya mengedepankan estetika lingkungan saja tetapi dapat meningkatkan perekonomian warga dan juga menjaga hubungan yang baik dalam bertetangga. Selain itu Kampung Romantis aktif dalam mempertahankan dan 
memperkenalkan budaya kepada generasi muda dan juga pendatang. Salah satu perayaan tahunan yang sering diselenggarakan adalah upacara Grebek Suro yang masih diperingati. Meskipun dilaksanakan secara sederhana perayaan Grebek Suro ini dapat menumbuhkan perasaan bangga dan cinta akan budaya asli Indonesia. Dalam hal ini, terdapat potensi dari aspek tangible (fisik) dan intangible (non fisik) yang dapat dikembangkan menjadi wisata minat khusus di kota Malang (Susanti, Agustin, \& Mutia, 2020).

Langkah awal yang perlu dilakukan untuk mengembangkan kampung romatis yaitu dengan mengenalkan kampung romantis kepada wisatawan, salah satu media promosi tersebut yaitu dengan memperkuat identitas visual kawasan seperti logo sebagai penguat citra merek dari suatu kampung wisata. Signage merupakan salah satu bagian dari logo yang memperkenalkan dan media promosi yang sesuai dengan kebutuhan kampung romantis. Dalam hal ini, signage diperlukan sebagai logo identitas sekaligus penunjang dari objek wisata (Christianna, 2016). Menurut (Ruan, Long, Zhang, and $\mathrm{Wu}, 2016)$, signage berperan penting dalam memandu wisatawan dan meningkatkan kualitas pengalaman pariwisata. Signage merupakan suatu bidang grafis yang mengkomunikasikan infomasi dalam membentuk sebuah lingkungan. Informasi yang dikomunikasikan berupa komunikasi grafis.

Aktivitas dari Environmental Graphic Design (EGD) melibatkan pengembangan sistematis, sistem informasi kohesif dan sistem komunikasi visual grafis pada sebuah situs dengan lingkungan yang dibangun (Calori \& Vanden-Eynden, 2015). Pada kegiatan pengabdian kepada masyarakat signage kawasan menjadi perhatian utama, karena untuk memperkenalkan kampung romantis kepada wisatawan.

\section{METODE}

Lokasi kegiatan pengabdian ini tepatnya berada di RT 05 RW 04 kelurahan Bareng Kulon, kecamatan Klojen, Malang, yang lebih dikenal dengan kampung romantis. Adapun mitra dalam kegiatan pengabdian ini adalah Karang Taruna kelurahan Bareng, dengan melibatkan warga berjumlah sekitar 20 orang. Untuk pelaksanaan kegiatan dilakukan dengan menggunakan beberapa tahapan, yaitu:

Observasi: merupakan tahapan awal yang dilakukan sebagai bagian dari kegiatan survei awal untuk pengumpulan data primer di lapangan. Tujuan dari observasi yaitu untuk menganalisa permasalahan dan potensi pada lingkungan sekitar. Analisa dilakukan dengan mengamati aspek fisik dan non fisik yang ada di kampung romantis.

Komunikasi: merupakan tahapan lanjutan dari proses observasi. Komunikasi dilakukan dengan perangkat RT dan RW tentang hasil observasi. Dalam tahapan ini pada akhirnya mem-berikan solusi terhadap permasalahan yang dihadapi oleh kampung romantis. Salah satu permasalahannya kurangnya identitas yang memperkenalkan kawasan ini menjadi salah satu kampung tematik di Kota Malang.

Planning: Planing adalah tahapan untuk menyusun konsep desain signage yang menjadi solusi dari permasalahan pada kampung romantis. Dalam tahapan ini tetap melibatkan masyarakat tokoh masyarakat yaitu RT dan RW. Pada tahapan ini tidak hanya desain yang didiskusikan tetapi juga penempatan, material yang dipakai dan juga 
Available online at https:/jurnal.stmikroyal.ac.id/index.php/jurdimas

pelaksanaan di lapangan (time schedule). Sehingga pada tahapan ini menjadi Langkah awal dalam merencanakan desain sekaligus tahapan eksekusi desain di lapangan. Untuk mendukung tahapan ini biasanya dibuat modeling agar lebih representatif dan mudah dikomunikasikan dengan warga.

Konstruksi: Tahapan ini adalah tahapan eksekusi dilapangan. Pada tahapan ini juga melibatkan warga sehingga partisipasi warga masih diperlukan.

\section{PEMBAHASAN}

Sebelum memasuki proses desain signage dilakukan pembagian kuesioner kepada warga RT 5 untuk mengidentifikasi potensi dan karakter warga setempat. Hasil dari kuesioner dapat disimpulkan bahwa, Signage kawasan memiliki karakter yang lebih feminim (aspek bentuk dan warna) dengan menonjolkan kesan alami dan menggunakan fonts yang unik tetapi mudah dikenali. Signage adalah rangkaian representasi atau wujud visual dan simbolik grafik, yang memiliki tujuan sebagai media interaksi dan komunikasi antara manusia dengan ruang publik. (Andrijanto, 2018). Signage juga memainkan peranan penting dalam memberikan impresi dan informasi tentang atraksi dan bisnis dalam suatu kawasan (Kellaris \& Machleit, 2016). Oleh karena itu, konsep signage kawasan yang dipilih adalah bentuk logo bunga.

Dalam hal ini, bentuk bunga sebagai salah satu representasi dari perasaan sayang (romantis) dan juga relevan dengan bisnis jual tanaman hias yang dilakukan oleh penduduk sekitar. Bunga daffodil dipilih untuk bentuk logo karena memiliki makna: permulaan baru, terlahir kembali, kreatifitas, inspirasi,

semangat, kesadaran, ingatan, dan pengampunan (Oktiani, 2020). Maknamakna tersebut sesuai dengan nilai visi dan misi kampung romantis.

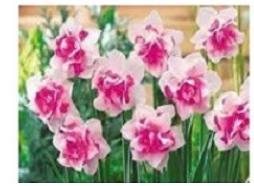

Gambar 1. Proses desain signage Kawasan

Stuktur Bunga daffodil mulai dari bentuk kelopak bunga dan juga warna tetap dipertahankan sehingga mudah dikenali ketika sudah diaplikasikan dalam bentuk signage kawasan. Penyangga signage kawasan dibuat dari batang untuk menunjukkan kesan alami. Font yang dipilih menggunakan jenis font hello valentica regular yang memiliki karakter lebih feminis dan menggambarkan lebih fleksibel dan dinamis. Pemilihan dan konsep warna juga merupakan hal penting dalam pembuatan signage pada lokasi objek wisata (Miazaki \& Setyadi, 2020). Oleh karena itu, pemilihan warna dipilih warna pink karena warna pink melambangkan perasaan romantis, lembut, menawan, dll. Warna yang dipilih perpaduan warna pink dengan tone yang berbeda, sehingga memberikan kesan yang dinamis dan atraktif.

\section{Proses sosialisasi desain kepada perangkat RT}

Proses sosialisasi ini dilakukan Ketika desain signage sudah final. Pada proses ini pihak kampung diwakili oleh perangkat RT. Sosialisasi desain disampaikan dengan cara presentasi disaksikan perangkan kampung dan dilakukan disalah satu rumah warga. Pada proses ini membahas tentang konsep desain signage, material yang akan digunakan, budget dan juga ukuran signage. Terdapat beberapa masukan yang diberikan oleh 
salah satu perangkat RT terkait dengan material tiang yang akan digunakan. Sehingga harus dilakukan revisi desain signage.

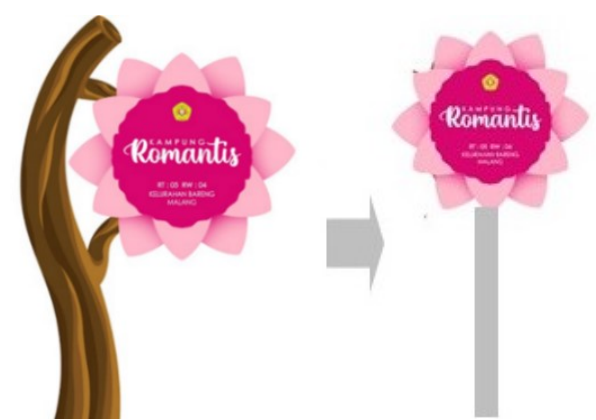

Gambar 2. Revisi Desain Signage

\section{Proses penentuan lokasi penempatan signage kawasan}

Penentuan lokasi penempatan signage Kawasan dilakukan berdasarkan keputusan Bersama dengan perangkat RT. Penempatan signage harus mempertimbangkan perilaku pengunjung dimana pengunjung dapat membuat keputusan serta titik utama suatu area (Hanifunisa \& Swasty, 2020). Oleh karena itu, penentuan lokasi penempatan signage didasarkan atas beberapa pertimbangan yaitu: Kemudahan wisatawan mengidentifikasi signage, Arah hadap signage, dan Aksesbilitas Kawasan.

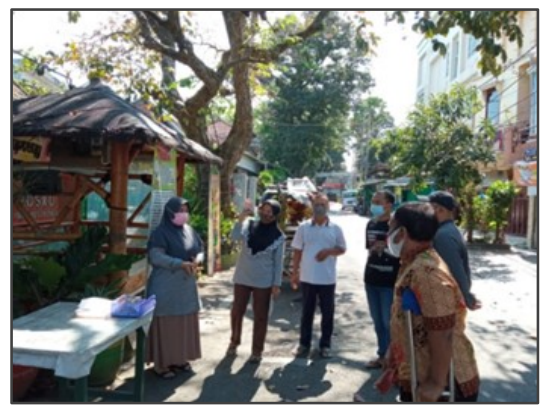

Gambar 3. Lokasi pemasangan Signage

\section{Pelaksanaan Konstruksi Lapangan}

Pelaksanaan konstruksi di lapangan dilakukan dengan melibatkan warga. Warga aktif dalam membantu proses konstrusi di lapangan.

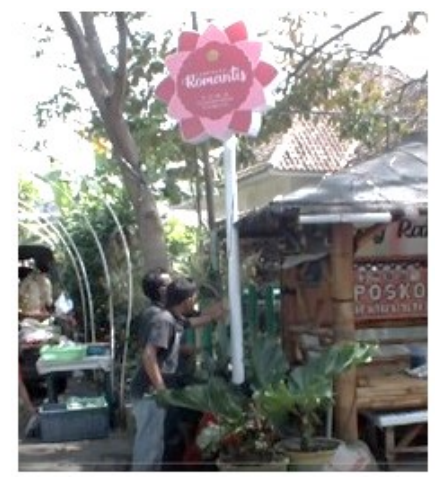

Gambar 4. Proses konstrusi signage

\section{Evaluasi signage kawasan}

Signage kawasan yang ditempatkan pada area publik dan menjadi pusat kegiatan kampung romantis, sehingga memudahkan wisatawan untuk melihat baik pada siang atau malam hari.

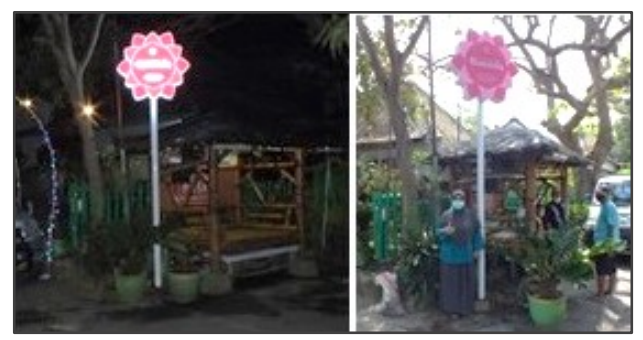

Gambar 5. Proses konstrusi signage kawasan

\section{SIMPULAN}

Kegiatan pengabdian telah berhasil dilakukan dengan menciptakan desain signage dan wujud fisiknya (konstruksi) dengan keterlibatan masyarakat sekitar. Signage Kawasan merupakan salah satu upaya agar warga kampung romantis dapat memperkenalkan kampung tematik baru di kota Malang kepada wisatawan. Selain sebagai ajang promosi signage kawasan ini merupakan salah satu cara untuk membranding kawasan dengan memperkenal icon (bunga daffodil) kampung romantic, dengan dibangunnya signage kawasan maka akan 
Available online at https:/jurnal.stmikroyal.ac.id/index.php/jurdimas

memberikan semangat lebih kepada warga untuk dapat mengembangkan dan memperkenalkan kampung romantis.

\section{UCAPAN TERIMA KASIH}

Terima kasih kami ucapkan kepada Progdi Arsitektur UPNVJT dan juga LPPM UPNVJT yang telah membantu dan mendanai kegiatan pengabdian kepada masyarakat ini.

\section{DAFTAR PUSTAKA}

Andrijanto, M. (2018). Perancangan Alternatif Sign System Sebagai Informasi Lokasi Penjualan Di Pasar Legi Kota Gede. Jurnal Desain, 5(03), 223-234.

Anggraini, L., \& Nathalia, K. (2014). Desain Komunikasi Visual dasardasar panduan untuk pemula. Bandung: Nuansa Cendekia.

Calori, C., \& Vanden-Eynden, D. (2015). Signage and wayfinding design: a complete guide to creating environmental graphic design systems: John Wiley \& Sons.

Christianna, A. (2016). Desain Signage Sebagai Solusi Pencemaran Visual. Paper presented at the Prosiding Seminar Nasional Lingkungan Hidup.

Hanifunisa, A., \& Swasty, W. (2020). Signage yang Informatif dan Interaktif pada The Heritage Palace Kota Surakarta Jawa Tengah. Jurnal Bahasa Rupa, 3(2), 95-103.

Kellaris, J. J., \& Machleit, K. A. (2016). Signage as Marketing Communication.
Interdisciplinary Journal of Signage and Wayfinding, 1(1).

Miazaki, R. B., \& Setyadi, D. I. (2020). Perancangan Desain Grafis Lingkungan Museum Maritim Surabaya North Quay di Pelabuhan Tanjung Perak Surabaya. Jurnal Sains dan Seni ITS, 8(2), F294-F299.

Nurjani, N. P. S. (2021). Dinamika Kampung Kota Berkelanjutan Di Tengah Pandemi Covid-19. Jurnal Ilmiah Vastuwidya, 4(1), 26-32.

Oktiani, V. (2020). Bunga Daffodil, Filosofi dan Manfaat di Balik Bunga yang Cantik Tapi Beracun. Retrieved from.

Ramadhana, B., Rahardjo, P., \& Wipranata, I. (2019). Penataan Kampung Wisata Kreatif Dago Pojok Bandung. Jurnal Sains, Teknologi, Urban, Perancangan, Arsitektur (Stupa), 1(2), 23132322.

Ruan, L., Long, Y., Zhang, L., \& Wu, X. L. (2016). A Geographic Analysis Of Optimal Signage Location Selection In Scenic Area. International Archives of the Photogrammetry, Remote Sensing \& Spatial Information Sciences, 41.

Susanti, W. D., Agustin, D., \& Mutia, F. (2020). Kajian Genius Loci Pada Kampoeng Heritage Kajoetangan Malang. JURNAL ARSITEKTUR, 10(2), 85-94.

Wiwin, I. W. (2019). Wisata Minat Khusus sebagai Alternatif Pengembangan Pariwisata di Kabupaten Bangli. Pariwisata Budaya: Jurnal Ilmiah Agama Dan Budaya, 2(2), 42-52. 